\title{
Unconventional Story: A Future with Shale Gas and Other Unconventional Resources. A Look from Russia
}

\author{
Leonid Anisimov \\ LUKOIL-Engineering Limited, VolgogradNIPImorneft, Branch Office in Volgograd, Russia
}

Received: January 15, 2016 / Accepted: February 16, 2016 / Published: April 30, 2016.

\begin{abstract}
The main achievements in the development of hardly-recoverable resources are currently associated with shale oil and gas. The result of the "shale revolution" was billions of dollars in losses for oil exporters. The question is how this situation will be long-lasting or "shale bubble" will burst. The success of the shale revolution can be not only an economic win or economic defeat of the United States, the question is about reputation as a global political leader and the country's ability to solve the most difficult technological problems. Everything at stake to extend the "shale gas revolution" as it is possible longer, in time to prepare the conditions and technologies for a new energy revolution and to maintain the usual high level of energy consumption. The situation is further complicated by the introduction in the game of OPEC (organization of petroleum exporting countries) causing oil prices dropped below the cost of shale oil. The future of high technology in the production of oil depends on whether exporters and importers to negotiate the best price for oil, to ensure the sustainable development of the world economy.
\end{abstract}

Key words: Shale revolution, unconventional resources, petroleum technologies, oil prices.

\section{Struggling for the Energy Independence}

The developments of recent years in the oil and gas industry for many in Russia were unexpected. The market dumped a significant amount of oil and gas that belonged to the category of "shale", which means tight, biding its time in the distant future. The result of the "shale revolution" was billions of dollars in losses for Russian exporters. The question is how this situation will be long-lasting or "shale bubble" will burst, or we can expect a long tough job for a place under the sun in the conditions of tough competition with alternative unconventional sources of hydrocarbons.

The "shale revolution" was inevitable, but it came in earlier than expected.

Development of traditional oil field consists of several stages. At the first stage, the oil is extracted in a natural mode, it flows to the bottom of the well, due to the energy of the reservoir. So you can get

Corresponding author: Leonid Anisimov, professor, research field: petroleum geology.
$15 \%-20 \%$, at best $30 \%$ of the oil. The next stage is the flooding of the reservoirs or the pumping of gas, which maintains reservoir pressure. So you can get another $15 \%-20 \%$ oil.

The next step is the use of "tertiary", hydro-fracturing, chemical and thermal effect. So you can get another 15\%-20\% oil. The transition to each new stage increases the cost of oil and the development of "tertiary" is possible in relatively cheap technologies to produce oil below its market value. USA, who first began to produce oil in large volumes from numerous fields have long switched to 2 and 3 stages of development. In other countries, the situation is better, many of the deposits so far developed in a natural mode. In these circumstances, the U.S. should consider how to use their political, economic and technological opportunities to ensure energy independence.

The issue of energy independence was actively considered in 2006, when after a long break resumed the conference on oil shale in Colorado. Author was a 
participant. The most memorable scene emphasized the replication of pictures of Putin and Chavez, and comments were reminiscent of a typical American Thriller: The United States is facing an unprecedented challenge to its dependence on foreign oil and gas, especially from fuel imports from politically unstable and unfriendly countries. "Venezuela increases oil exports to China, enters into agreements with Russia on construction of refineries and the use of atomic energy". This advocacy support led to the mobilization of economic and technological capabilities of the country to solve its energy problems.

\section{Unconventional Resources of Hydrocarbons}

The main achievements in the development of hardly-recoverable resources are currently associated with shale, lying at a small depth (oil shale) and hydrocarbons mainly composed of clayey formations, which occur at considerable depth (shale oil and shale gas). In 2005, the US Department of Energy announced the results of field studies to assess oil shale resources in the country [1]. What was reported was stunning news (or well forgotten old facts $[2,3]$ ): It turned out that, in the USA, more oil than in all other studied deposits in the world. Below are the official numbers:

- 8 times more oil than in Saudi Arabia;

- 8 times more oil than Iraq;

- 21 times more oil than in Kuwait;

- 22 times more oil than in Iran;

- 500 times more oil than Yemen.

And all located in the Western part of the United States of America, in the Rocky mountains, according to American geologists. "We have, on this compact site, more oil than all the Middle East, more than 2 trillion barrels. Untouched. It's more than it is estimated today oil resources in the World." In response to a question about the famous oil, senator of Utah Orrin said, "the amount of oil is staggering. Who would have guessed that, in just Colorado and Utah, industrial oil reserves are more than in the Middle East. Here's the thing".

Formation Green River is the most rich not only in the U.S. but throughout the world. Proven geological reserves of oil in shale are expected to reach 440 billion tons of standard fuel, which is $91 \%$ of all known reserves of oil shale in the U.S. and $64 \%$ of the known reserves of oil shale around the globe. Formation Green River was formed in the Eocene sediments from the largest freshwater lakes and is currently confined to four virtually isolated basins with a total area of 65 thousand $\mathrm{km}^{2}$.

However, the most outstanding technological breakthrough associated with the development of shale gas and shale oil. Assessment resources in the United States and Canada showed that, they are approximately equal resources of traditional hydrocarbons [4]. At the same time, their development is more labor intensive and much more expensive. It is believed that, the shale formation is the source layer, the collector and the seal. Area oil and gas accumulations are confined to "traditional" limited by the size of the reservoirs and adjacent rocks of uncompacted clay, forming "composite" tanks.

Clay does not have a rigid skeleton, so the recovery of them depends on the initial reservoir pressure and the nature of deformation. The creation of an extensive network of cracks and their consolidation allows you to combine in a single system separate pores and ensure reliable communication with the well.

Shale oil is painted as a potential source of oil for over a hundred years for countries around the world, but the country has not evolved in this direction, because of the high cost of the process of extracting oil from shale and damage to natural resources.

Pessimists especially indicate the temporary nature of success in the growth of oil and gas [5, 6]. There are geological, technological and environmental reasons. In fact, the U.S. is the only country in the world where the raw material is mined shale. It has 
been drilled millions of wells for oil and gas and for the development of "shale gas" has selected the most promising areas. All attempts to repeat the success in other countries is not successful. American corporations were drilling in Poland, where shale gas reserves were estimated at trillions of cubic meters. The project has been given much attention, as Poland for decades wants to get rid of the "energy stranglehold" on the part of Russia. But the results of drilling do not allowed the companies Exxon Mobil and Total to start real exploitation of shale gas.

A lot of hope to other countries of Europe, in particular on the Ukrainian fields in the Donetsk and Lviv regions. In all cases, commercial production was always postponed for the "near future" and this continued for several times.

The cost of shale oil and shale gas is significantly higher than traditional. Experts estimate the average cost of production of shale oil in the US is about $\$ 48$ per barrel. With the current cost of oil on the world market, its production is quite justified. As for shale gas, the cost of mining is approximately equal to $\$ 200$ per 1,000 cubic meters, which is lower than the cost offered by monopolists in Europe.

\section{High Technologies}

The largest companies spent their funds for long-term experiments to see whether they could produce oil from oil shale, heating the rock in place, avoiding, thus, environmental problems associated with mining. Representatives of Shell Company said that, they will not take decisions on commercial feasibility of industrial use of oil shale until the end of this decade.

In Europe, the most advanced country in the use of energy oil shale is Estonia, which got the oil shale sector after the collapse of the Soviet Union. No less hopes associated with the Volga shale, which were widely used in the pre-war period.

Unique explored the potential of alternative hydrocarbons, located in the European part of Russia up to the present time is not in demand because of features of geological deposits: thickness ranges from $0.3 \mathrm{~m}$ to $0.9 \mathrm{~m}$, the capacity of the inter-layer clays from $2.5 \mathrm{~m}$ to $4 \mathrm{~m}$. To develop these deposits with traditional mining way, is not profitable from the economic side and not acceptable from an environmental. For each ton of extracted fossil will need to produce 4-5 tons empty interslate rocks, to accommodate the tailings that will be with $\mathrm{H}_{2} \mathrm{~S}$.

Concerning shale gas and shale oil accumulated by oil companies technological, financial and scientific potential will allow to occupy a leading position in addressing this vital energy issue.

To increase its output of shale hydrocarbons, conduct hydraulic fracturing in the borehole under high pressure is fed large quantities of water and it breaks the formation. Also in the well run about 300 tons of coarse sand for fixing cracks, and about 200 tons of chemicals (benzene, toluene, phenols, hydrochloric acid, and other) for washing and improve permeability. In operations, hydraulic fracturing has several dozen units, which together pumped into the borehole the reactants. Their total capacity reaches 50 thousand horsepower.

But there are growing environmental problems. The separated horizons are connected by a system of cracks, it provokes beginning inter-layer flows of water, hydrocarbon and process fluids [7]. When developing wells pump toxic reagents, it requires reliable burials. In this regard, there are numerous specific examples of contamination of various areas of mining (especially of soil and water and even air) in the United States, and the actual abandonment of the production of entire States like California and New York, as well as almost all European States.

The success of the shale revolution can be not only an economic win or economic defeat of the United States; the question is about reputation as a global political leader and the country's ability to solve the most difficult technological problems. Otherwise, putting in the world the wrong way, the USA may incur significant moral costs. Everything at stake to 
extend the "shale gas revolution" as it is possible longer, in time to prepare the conditions and technologies for a new energy revolution and to maintain the usual high level of energy consumption.

The situation is reminiscent of the paintings of the race after a criminal, that Mayne Reid described in his famous novel "The Headless Horseman".

"There is but one of the pursuing parties who continues to keep him in view - a tall man, mounted upon what might be taken for the sorriest of steeds - an old mustang mare. Her speed tells a different tale; produced though it be by the strangest of spurs - the keen blade of a bowie-knife. It is Zeb Stump who makes use of this quaint, but cruel, means of persuasion.

Still the old mare cannot keep pace with the magnificent stallion of the mustanger. Nor does Zeb expect it. He but aims at holding the latter in sight, and in this he is so far successful."

And in our case, when we have to produce a lot of oil and gas from poor reservoirs, we have to loosen rocks at a depth, in large volume, on the vast territory and to pump and extract a lot of toxic reagents. It is a tough job.

\section{A Stab in the Back}

"The one constant in life is change, there will be unforeseen events." In January 2016, the global price of oil traded near $\$ 30$, down 70 percent from its high for the last years of $\$ 115$.

It would be naive to think that the organization of petroleum exporting countries is satisfied with the price of \$30-50 per barrel in the long run. So the price is $\$ 100$ per barrel is more attractive but it is necessary to eliminate competitors. Shale oil in the USA has become the main competitor of conventional oil, and the most convenient way to remove it is to reduce the price below the cost of production of shale oil. Now OPEC is waiting for the funeral of shale projects. OPEC's biggest producers remain very profitable at low oil prices because the cost to produce oil there is far below even current oil prices. Saudi Arabia, the United Arab Emirates and Kuwait have large foreign reserve funds that will help them withstand periods of low prices, though they may still trim spending in response to these prices. The world's four biggest economies-U.S., China, Japan and that of the European Union-all benefit from lower oil prices. Federal Reserve chair Janet Yellen said that, the decline in energy prices is "likely to be a net positive", for the U.S., even if it decreases domestic drilling activity, because the country remains a net importer of oil [8]. The state economy is higher than the oil industry. This is an important event for the USA because of the changes in opinion on the priority of energy independence.

The oil prices punish the economies of some major exporters. Russia needs to reform its economy to escape from energy dependence. This is bitter medicine, but should be treated. This is a paradox in comparison with the USA.

\section{Conclusions}

The shale revolution has outlined a corridor of oil prices, optimal for the sustainable development of the world economy. It is $70-100 \$$ per barrel. Otherwise, there will be winners and losers. But it is not a long-term perspective. Markets of losers fail and the winners will lose them as well. Economic factors of development will be substituted with the political and then military. Hopes for a harmonious international development disappear. All become losers. This is such an unconventional story.

\section{References}

[1] Bartis, J. T., LaTourrette, T., Dixon, L., Peterson, D. J., and Cecchine, G. 2005. Oil Shale Development in the United States: Prospects and Policy Issues. Santa Monica, CA: RAND Corporation. Accessed March 6, 2016. http://www.rand.org/pubs/monographs/2005/RAND_MG 414.pdf.

[2] Donnell, J. R. 1964. "Geology and Oil-Shale Resources of the Green River Formation." In Proceedings of the First Symposium on Oil Shale, 153-63. 
Resources. A Look from Russia

[3] Dyni, J. R. 2003. "Geology and Resources of Some World Oil-Shale Deposits." Oil Shale 20 (3): 193-252.

[4] European Commission. Joint Research Centre. 2012. Unconventional Gas Potential Energy Market in the European Union. Scientific and policy reports.

[5] Hughes, D. 2011. Will Natural Gas Fuel America in 21st Century? Report of the Post Carbon Institute.

[6] Hughes, D. 2013. Drill, Baby, Drill: Can Unconventional
Fuels Usher in New Era of Energy Abundance? Report of the Post Carbon Institute.

[7] Resources Defense Council. 2012. "Fracking Facts. Protecting Americans from the Risks of Fracking." Resources Defense Council. Accessed March 6, 2016. http://www. nrdc.org/energy/files/frackingrisks.

[8] Fahey, J. 2014. Global Oil Impact: Who's Hurting, Happy, Hopeful. New York: Associated Press. Accessed December 19, 2014. http://www. wtop.com. 